\title{
A Lei Maria da Penha Auxiliando na Construção da Igualdade de Gênero: uma análise da situação e percepção social da violência doméstica contra a mulher em Campina Grande (PB)
}

\author{
The Maria da Penha Law Assisting in the Construction of Gender \\ Equality: an analysis of the situation and social perception of domestic \\ violence against women in Campina Grande (PB)
}

\author{
Antônio Cardoso Silva Filho \\ Universidade Estadual da Paraíba - Brasil \\ tonycardoso.geo@hotmail.com \\ Janaína Barbosa Silva \\ Universidade Federal de Campina Grande - Brasil \\ janainasimov@yahoo.com.br
}

\section{Resumo}

Esta pesquisa teve como objetivo analisar a percepção social quanto a Lei Maria da Penha e sua interferência na construção da igualdade de gênero no espaço urbano de Campina Grande-PB. Para tanto, utilizou-se dos seguintes procedimentos: a) levantamento de dados; b) espacialização em ambiente SIG; c) aplicação de questionários; d) realização de grupos focais. Constatou-se que os bairros que apresentam o menor índice de denúncia de violência doméstica contra mulher não são necessariamente os mesmos que dispõem da menor quantidade de ocorrência. Sendo este fato resultante do não conhecimento da Lei e de questões socioeconômicas de acordo com o discurso da população feminina destas áreas de destaque na cidade de Campina Grande-PB.

Palavras-Chave: Análise Socioespacial; Lei $\mathrm{N}^{\mathrm{o}}$ 11.340; Interdisciplinaridade..

\begin{abstract}
This research aimed to examine the social perception of the Maria da Penha Law and its interference in the construction of gender equality in the urban area of Campina Grande (PB). For this, the following procedures were adopted: a) data collection, b) spatialization in GIS environment c) questionnaires d) conducting of focus groups. It was found that the districts that have the lowest rate of reportings of domestic violence against women are not necessarily the same ones that have the least amount of occurrences, and this fact is the result of a lack of knowledge of the Law and of socioeconomic issues, according to the discourse of the female population of these highlighted areas in Campina Grande.
\end{abstract}

Keywords: Socio-Spatial Analysis; Law N ${ }^{\circ}$ 11,340; Interdisciplinarity. 


\section{Introdução}

A violência doméstica contra mulher se manifesta como problema interdisciplinar especialmente pelo fato de estar associada às distinções entre a articulação do crime, da violência, dos seus efeitos e das relações intrínsecas pelo gênero, como também pelas condições socioespaciais que condicionam, em parte, tal configuração.

Diversos estudos e pesquisas mais amplamente divulgadas condicionaram análises ao longo do tempo, que associam a violência contra mulher a uma perspectiva estreitamente feminista, da qual abarca uma série de teorias formuladas por heranças filosóficas e sociológicas (SAFIOTTI, 2004). $\mathrm{O}$ desenvolvimento epistemológico desta linha de pensamento apresenta variações de conquistas e anseios, que por si só, refletiram em modificações socais do papel da mulher paralelas à evolução desde o feminismo liberal até o estruturalista (NYE, 1995). Este último, marcado pelo reconhecimento de que a natureza ou qualquer realidade física ou de pensamento que determina a posição inferior das mulheres em relação aos homens, é resultante de componentes semânticos de dominância masculinizados nas palavras, fazendo com que a inferioridade das mulheres seja codificada na linguagem e no discurso da sociedade (LACAN, 1982).

De acordo com Safiotti (2004) dois conceitos são de extrema importância para o desenvolvimento de análises e propostas relacionadas ao pensamento feminista: Patriarcado e gênero. Quanto ao patriarcado, supõem-se que as relações marcadas entre o feminino e o masculino são desiguais e hierarquicamente baseadas, sobretudo, nas diferenças físicas, sexuais e biológicas apresentadas por homens e mulheres. Por sua vez, o gênero, assumindo uma denotação mais ampla, enfatiza a consolidação do feminino e do masculino através de uma construção social marcada por aparelhos semióticos, como por exemplo, símbolos culturais de interpretação de significados, organizações, instituições sociais e identidade subjetiva (LAURETIS, 1987; SCOTT, 1988).

Em geral, acredita-se que por ter havido primazia masculina no passado, as questões patriarcais exerceram grande influência nas análises que apresentavam de forma dialética o masculino e o feminino. Porém, a utilização unicamente do conceito de gênero para trabalhar as questões feministas é recusado por vários estudiosos (LERNER, 1986; JHONSON, 1997; SAFIOTTI, 2004). Estes autores enfatizam que tal conceito, representando uma construção social do masculino e feminino, não explicita, necessariamente, as desigualdades entre homens e mulheres. Assim, a necessidade de utilizar o conceito de gênero como categoria geral de análise e o conceito de patriarcado como categoria específica de determinado período da humanidade, pode ser ressaltada como uma alternativa complexa na busca de uma plenitude conceitual para se trabalhar determinados aspectos que envolvam o homem e a mulher, o masculino e o feminino.

Neste contexto, ressaltado o reconhecimento da importância das linhas de pensamento feministas na construção da igualdade entre homens e mulheres e o conceito de gênero englobando a construção das identidades masculinas e femininas, pode-se estabelecer um elo para o entendimento e discussão da complexidade que envolve as teorias, os conceitos, as problemáticas vivenciadas e a formulação de normatizações baseadas em todos estes fatores.

A violência contra mulher é caracterizada neste cenário como violência de gênero representada por relações de poder e dominação do masculino e da submissão do feminino (BIANCHINI, 2013; TELES \& MELO, 2004). Pesquisas apontam a 
ocorrência mundial deste problema através de dados alarmantes. No Brasil, por exemplo, em um universo de 1.800 mulheres entre $15 \mathrm{e}$ 49 anos, $62 \%$ afirmam já ter mantido relações sexuais contra a vontade; $7 \%$ declararam ter sido submetida à violência física; $23 \%$ a alguma forma de coerção e; $32 \%$ afirmaram sua obrigação em aceitar a imposição do marido, noivo ou companheiro (ANDALAFT \& FAÚNDES, 2001).

Minayo (2006) afirma a multiplicidade da violência contra mulher, reconhecendo esta como um problema complexo e existente de forma diferenciada em sua dimensão jurídica e espacial. Logo, questiona-se sobre os desafios envolvidos no intercâmbio entre as expressões desta violência e as diferentes formas de investigação científica. Esse diálogo programa a construção de um debate que reconheça a complexidade do real e suas interferências indissociáveis com diversos problemas sociais, dentre eles a violência contra mulher.

A violência doméstica contra mulher, ganha destaque expressivo nesta discussão por ser caracterizada como a mais incidente dos tipos de violência contra a mulher no Brasil (ROLIM, 2008). Ademais, de acordo com a pesquisa realizada pela Fundação Perseu Abramo, em 2001, o percentual em que o marido ou parceiro é o agressor da violência intrafamiliar variou entre $53 \%$ a $70 \%$ dos casos notificados.

No que se refere à definição da violência doméstica contra mulher, Jesus (2010) afirma que pode ser caracterizada a partir de duas variáveis: quem agride e onde agride. Logo, para que a violência seja enquadrada como conjugal, é necessário que o agressor seja uma pessoa que frequente sua casa, ou cuja casa ela frequente, ou que more com ela independente da denominação. $O$ espaço doméstico incide como segunda variável no sentido de delimitar o agressor como pessoa que tem livre acesso a ele.
A afirmativa de que há certa vulnerabilidade da mulher no lar é indicada por Biachini (2013) visto sua maior exposição ao agressor, como também ao fato das ocorrências serem predominantemente no lar pelos seus maridos e companheiros. Em suma, a violência doméstica é aquela perpetrada em ambiente doméstico, familiar ou de intimidade e afeto, enquanto a violência de gênero ocorre em razão do feminino, seja em ambiente doméstico ou não.

A Lei ${ }^{\circ} 11.340$ de 07 de agosto de 2006, popularmente conhecida como Maria da Penha, motivada e elaborada pela constante ocorrência da violência doméstica contra a mulher (PARODI \& GAMA, 2009), incide em meio à violência contra mulher e a violência de gênero.

Sendo assim, percebe-se que para a aplicação da Lei Maria da Penha é necessária que a violência acometida tenha ocorrido no âmbito doméstico e ainda tenha por base o gênero. Ou seja, a correspondente Lei, utiliza na sua aplicação uma associação entre a violência contra mulher, à violência doméstica e a condição de gênero, ou mais precisamente, o fato de sentir-se mulher e apresentar certo grau de vulnerabilidade na relação, uma vez que o gênero é relativo a uma construção social, devendo este estar relacionado de alguma forma a causa da violência. Nesta concepção, está também pode ser aplicada em casos de violência doméstica em relações homoafetivas, uma vez que as relações pessoais enunciadas na Lei independem da orientação sexual (LEI 11.340/2006).

Tendo em vista a complexidade da formulação e estruturação da Lei Maria da Penha, destacam-se as formas de violência previstas, sendo elas evidenciadas nos incisos do art. $5^{\circ}$ como violência física, psicológica, sexual, patrimonial e moral. A violência física é entendida como toda e qualquer conduta que ofenda a integralidade física ou saúde 
corporal da mulher com uso da força. Por violência psicológica entende-se qualquer conduta que cause dano emocional e diminuição da autoestima, que prejudique e perturbe o pleno desenvolvimento ou que vise degradar ou controlar ações, comportamentos, crenças e decisões. A violência sexual pode ser manifestada a partir de condutas práticas mediante: intimidação, coação, ameaça e uso da força que constranja a mulher a presenciar, manter ou participar de relação sexual não desejada. Já a violência patrimonial é vista através de toda conduta que configure retenção, subtração ou destruição dos objetos, instrumentos de trabalho, documentos pessoais, bens, valores, direitos ou recursos econômicos da vítima. Finalmente, a violência moral atinge qualquer ação que configure calúnia, difamação ou injúria (LEI 11.340/2006).

Segundo Greco (2010) a calúnia é o mais grave de todos os crimes contra a honra prevista pelo vigente Código Penal Brasileiro, ocorrendo com ato de imputar falsamente a alguém, fato definido como crime. Por outro lado, a difamação se caracteriza como a impulsão de fato ofensiva a reputação de outrem. A injúria, por conseguinte, se dá com ofensa da dignidade ou decoro da vítima.

Considerada como uma afronta à dignidade a vida humana, a violência doméstica contra a mulher deve ser adentrada por diferentes áreas do conhecimento, além de ser entendida no seio popular, de modo que não baste que os diretos sejam assegurados formalmente sem que haja uma compreensão geral da questão por parte da sociedade civil. Pandolfi (1999) afirma que é necessário que a população conheça, reconheça e possa usufruir dos seus direitos. É a partir deste diálogo que passa a ser importante analisar as condições socioespaciais de determinada localidade, haja vista que segundo Santos (2009) o espaço é um conjunto indissociado de ações e objetos que reflete diretamente nos processos sociais. Este autor propõe o desenvolvimento do conceito de socioespacial considerando tanto o espaço, quanto os processos sociais que resultam e são resultados destes sistemas de objetos e ações. Assim, percebe-se que as condições socioespaciais podem interferir diretamente na violência em si, como na oportunidade de obtenção de informações acerca da legislação que tratam os diferentes tipos de violência (MATOS, 2011; MINAYO, 1994).

Nesse sentido, Abdala et al (2011) ressaltam que a falta de informação por parte da mulher em relação à Lei Maria da Penha, acaba por deixá-la vulnerável a sofrer interferências em suas decisões no momento da denúncia de alguma forma de agressão, e até mesmo do reconhecimento de que está sendo violentada.

Diante do exposto, surgem diversos questionamentos dentre os quais se destacam: Quais os bairros que apresentam maiores e menores incidências de denunciação de violência doméstica contra mulher em Campina Grande-PB? Quais as principais formas perpetradas? Qual o grau de conhecimento acerca da Lei por parte da população? Existe uma relação socioespacial com a distribuição dos índices de denúncia? Quais os principais inibidores e propulsores deste tipo de violência de acordo com o discurso dos cidadãos? De que forma a Lei Maria da Penha auxilia na construção da igualdade de gênero no espaço urbano investigado?

Assim, esta pesquisa teve como objetivo analisar a percepção social quanto a Lei Maria da Penha e sua interferência na construção da igualdade de gênero no espaço urbano de Campina Grande-PB. Especificamente, identificando quais os bairros com menor e maior índice de denunciação deste tipo de violência e as principais formas perpetuadas, verificando os 
níveis de conhecimentos diferenciados sobre a Lei nas correspondentes localidades e identificando a partir do discurso da população local os principais propulsores e inibidores da violência doméstica contra mulher.

Trata-se de um trabalho complexo que busca: triangular impressões normativas, sociais, espaciais, de discurso e de gênero para uma maior compreensão da realidade pontual do fenômeno da violência doméstica contra mulher e da interferência da Lei Maria da Penha na tão almejada igualdade entre homens e mulheres.

Finalmente, $\mathrm{o}$ trabalho encontra-se dividido em três etapas principais, além desta introdução. A primeira refere-se à descrição metodológica do percurso de investigação. A segunda apresenta os principais resultados e a discussão da pesquisa. A terceira e última, discorre sobre os principais aspectos conclusivos deste estudo.

\section{Procedimentos Metodológicos}

Para o desenvolvimento desta pesquisa, utilizou-se de uma abordagem metodológica que agrega desde dados pontuais voltados a denunciação, até métodos de pesquisas qualitativas para coleta de informações como o discurso da população. Sendo assim, desenvolveram-se os seguintes procedimentos práticos: a) levantamento de dados; b) espacialização em ambiente de Sistema de Informação Geográfica (SIG); c) aplicação de questionários; d) realização de grupos focais.

\section{Levantamento de Dados}

No âmbito deste item, foram coletados dados referentes à realização de denúncias de violência doméstica contra mulher em inquéritos registrados na Delegacia Especializada no Atendimento à Mulher de Campina Grande dos anos de 2011 e 2012.
$\mathrm{Na}$ totalidade, foram analisados 901 inquéritos policiais, dos quais se extraíram informações relacionadas à localidade de ocorrência da violência perpetrada e suas referentes formas (física, psicológica, sexual, patrimonial e moral).

Neste processo, paulatinamente, foi desenvolvido um banco de dados com as informações supracitadas, organizando os elementos condizentes à pesquisa e formulando seu agrupamento a um SIG para que posteriormente fosse possível a espacialização tanto dos índices de denunciação, quanto das formas de violência doméstica registradas contra a mulher em Campina Grande.

É substancial ressaltar que para a quantificação das incidências e formas de violência doméstica contra a mulher, não foi considerado o número de denúncias realizadas durante $o$ lapso temporal averiguado, mas sim, a quantidade de formas de violência acometidas em cada bairro e descritas em cada documento analisado.

\section{Espacialização dos Dados em Ambiente SIG}

O mapeamento dos dados de denunciação surge no sentido de proporcionar uma alternativa para visualização dos bairros que incidiram com maiores e menores índices de ocorrências registradas e as divergências quanto às formas acometidas.

É neste item que surgem as estimativas da violência doméstica contra mulher na Cidade, identificado o bairro com maior e menor índice, e obtendo um panorama geral acerca das distinções quanto às formas em que elas se manifestam.

Para a elaboração dos referidos mapas, utilizou-se de geoprocessamento através do software ArcGis 10 licenciado para o Laboratório de Cartografia Digital, Geoprocessamento e Sensoriamento Remoto do Centro de Humanidades $(\mathrm{CH})$ da 
Universidade Federal de Campina Grande (UFCG).

\section{Aplicação de Questionários}

A aplicação de questionários acorreu em dois bairros do Município: Catolé e Três Irmãs. $\mathrm{O}$ primeiro, por ter sido $\mathrm{o}$ mais incidente de denúncia e o segundo, o menos incidente. Nesta etapa, buscou-se entender acerca do conhecimento da Lei Maria da Penha nestas localidades especificas, pelo fato de terem apresentado dados importantes sobre a configuração da violência doméstica contra mulher em Campina Grande-PB.

Deste modo, para o cálculo estimativo por quotas, relacionado apenas ao quantitativo da população feminina dos respectivos Bairros, foi considerada a totalidade da população de mulheres maiores de 14 anos de idade para definição de quantos questionários seriam aplicados e que representasse uma amostra significativa. Assim, levando em consideração a totalidade da população feminina do Catolé (11.123) aplicou-se 110 questionários, enquanto no bairro Três Irmãs (6.357), 60 questionários (IBGE, 2010).

Esta técnica de coleta de informações estava divida em duas partes principais, que por sua vez, continham informações diversas acerca do autoconhecimento, de instrumentos de proteção, do aparato preventivo, do conhecimento dos direitos assegurados, da percepção quanto à aplicação de medidas, do entendimento de questões de gênero, do reconhecimento do agressor e da forma de violência, inserindo diversos itens observados na percepção da população quanto a Lei Maria da Penha. No que diz respeito à sua descrição, consistiu de questionamentos de múltiplas escolhas e abertos. A aplicação dos questionários ocorreu em locais de convívio social nos dois Bairros, como por exemplo, escolas, Unidades de Saúde, praças e etc.

Para o trabalho inicial com as informações coletadas durante este período, foi desenvolvida uma análise de conteúdo a partir das informações contidas no questionário, acreditando ser esta a alternativa mais consistente para conceber uma discussão interada com a realidade constatada quanto ao conhecimento da Lei por parte da população.

\section{Realização de Grupos Focais}

O grupo focal ocorreu em momentos diferenciados no Catolé e Três Irmãs com moradoras da área e mulheres que apresentam convívio diário nas localidades. Foram convidados para as duas atividades, tanto mulheres comuns de áreas extremas dos Bairros, como líderes comunitárias e comerciantes.

O objetivo desta etapa esteve relacionado à associação do discurso da população aos principais inibidores e propulsores da violência doméstica contra mulher.

De acordo com Minayo (2005) e Leme (2006) este método de pesquisa incide seu valor humano de formar opiniões e atitudes através da interação entre os sujeitos. Assim, as participantes do grupo focal expuseram suas principais opiniões e constatações através de técnicas de pesquisa utilizadas durante a atividade como, por exemplo, entrevistas, levantamento de imagens, relatos de experiência e etc.

Toda a atividade foi desenvolvida em uma Escola e em uma Associação de Moradores localizadas respectivamente nos bairros durante um período de um turno (03 horas). Para a apreciação das informações adquiridas neste item, foram associados procedimentos analíticos tais como a análise de discurso e a análise de conteúdo para compilação das falas e percepções dos participantes da atividade. 
A Lei Maria da Penha Auxiliando na Construção da Igualdade

de Gênero: uma análise da situação e percepção social da

violência doméstica contra a mulher em Campina Grande (PB)

\section{Resultados e Discussão}

Inicialmente, através do levantamento de dados e da espacialização das informações em ambiente SIG, observa-se a distribuição espacial da denúncia de violência doméstica contra mulher no período de 2011 a 2012 em Campina Grande-PB (Figura 01).

Tendo em vista a amplitude dos dados coletados referentes a toda a Cidade, foi possível representar espacialmente a situação específica de cada bairro quanto às denúncias, de modo que se desenvolveram padrões de classificação que variaram entre 20 casos registrados. Desta forma, classificaram-se os bairros que apresentaram de: 1 a 20; 21 a 40; 41 a 60; 61 a 80 e; 81 a 110 casos.
Nesta perspectiva, constataram-se em um primeiro momento os bairros que mais incidiram em números de ocorrências de denunciação: Catolé, Liberdade, Bodocongó e Malvinas, apresentando variações entre 81 a 110 casos. No entanto, nesta alternância, o Catolé foi o único no qual se registrou o quantitativo máximo de 110 casos.

A totalidade de três bairros destacou os níveis de ocorrência de denúncias variantes entre 61 a 80 casos, como também de 41 a 60 casos, enquanto onze bairros apresentaram o número de denúncias entre 21 a 40 casos. A maioria, 28 bairros, prestou incidência de denunciação variante entre 1 a 20 casos. De modo que apenas o bairro Três Irmãs comportou o número mínimo de um caso de ocorrência registrada junto a Delegacia da

Figura 01: Mapa da distribuição espacial das denúncias de violência doméstica contra mulher em Campina Grande-PB (2011 e 2012).

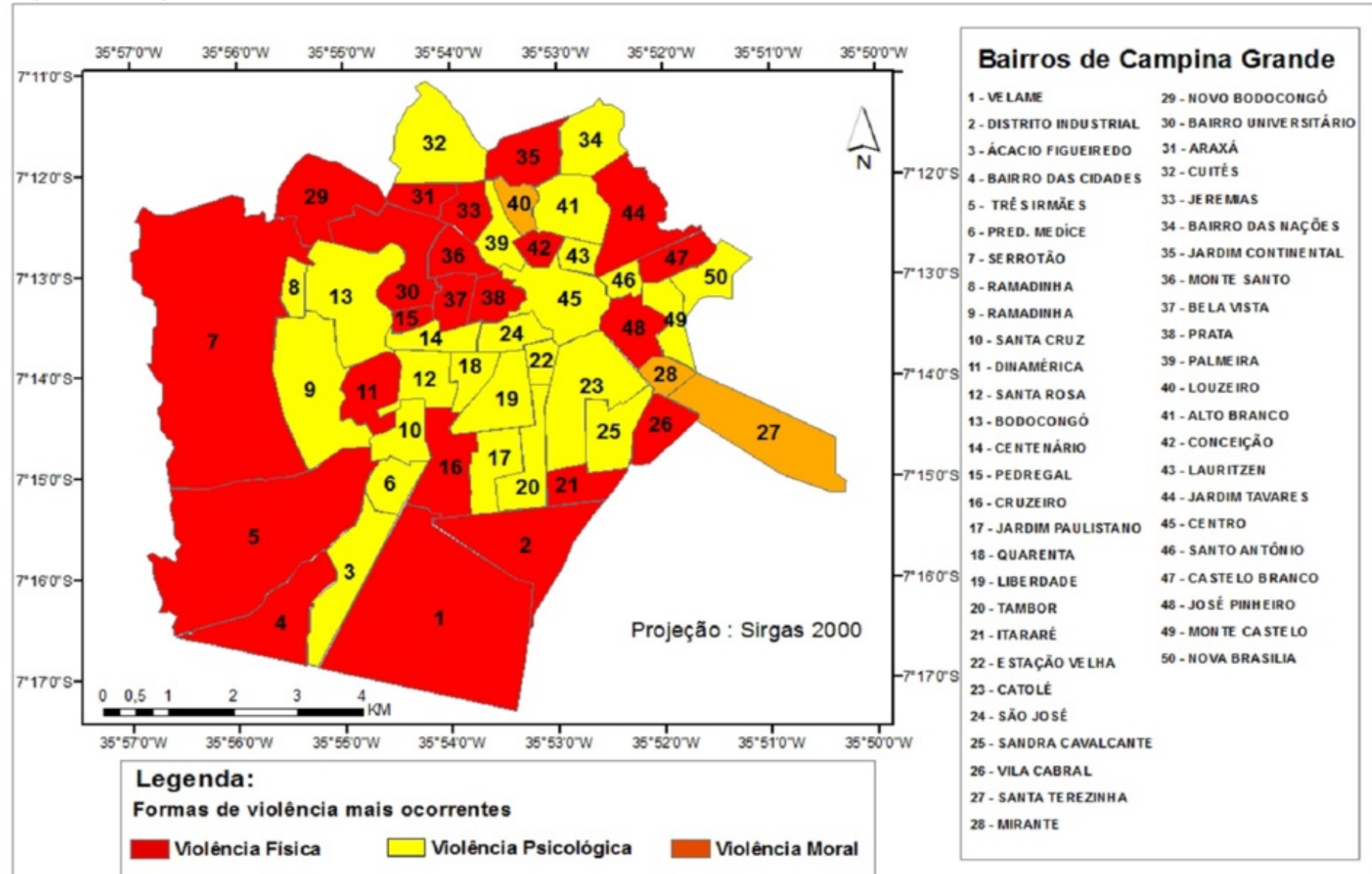


Mulher.

Em uma perspectiva espacial, verificou-se uma proximidade central dos bairros que apresentaram índices elevados de denunciação, de modo que os bairros periféricos localizados nas margens da Cidade, em termos de distância dos centros comerciais e imobiliários, ressaltaram os menores índices de denúncias. Sendo assim, conduzindo a discussão para uma análise socioespacial, questiona se de fato as localidades que dispõem das menores rendas domiciliares e de outros índices sociais não enfrentam a violência doméstica contra mulher de forma incisiva, comparando a outras localidades da Cidade, que por sua vez, detém simultaneamente uma diferente realidade social e apresenta a violência doméstica contra mulher a partir de um alto índice de denúncia. Em outras palavras, pode-se contestar sobre as condições que levaram determinadas localidades a apresentarem os menores e maiores índices de denúncia, ou mais especificamente se em determinados locais não há violência ou não há denúncia, além dos fatores que levam a esta configuração.

A partir de então, passa a ser importante considerar diversos outros elementos referentes a esta situação em Campina Grande-PB, de modo que existe o reconhecimento de que indicar a distribuição espacial das denúncias de violência doméstica contra mulher seria uma análise insuficiente para entender o fenômeno deste crime e a sua real manifestação. As políticas públicas de prevenção e controle de tal violência, também devem ser viabilizadas através de uma análise que contemplem todas as questões vinculadas a esta problemática, e não através apenas de uma exploração de dados, que muitas vezes não responderá de forma condizente à realidade complexa vivenciada quanto a esta enigmática realidade.
Logo, a necessidade de triangular diferentes informações e dados como, por exemplo, as principais formas de violência perpetradas nos diferentes bairros. Ou seja, quais as formas de violência foram mais notificadas em cada localidade da Cidade? Através disto, seria possível verificar as formas de violência reconhecidas pela população feminina, implementando outras discussões no contexto de investigação.

Trata-se do reconhecimento das limitações objetivas do direito quanto à lei e de métodos classificatórios e disjuntivos para a análise de um fator complexo. A violência doméstica contra mulher é vista então como um fenômeno passível da aplicação e sobreposição de análises multifacetárias. Só existe a denúncia através da identificação da existência da violência e de sua forma, esta, por sua vez, dependerá da capacidade de identificação de quem a sofre. Assim, a denúncia e as formas de violência doméstica contra a mulher não poderiam ser analisadas de maneira diferenciada.

Em suma, foram destacadas três formas de violências mais incidentes: Física, psicológica e moral (Figura 02). A violência psicológica foi a mais preponderante, apresentando-se em 25 bairros. A violência física surge em 22 bairros e a moral em três localidades. Entretanto, quando se relaciona a espacialização das formas de violência com a distribuição espacial das denúncias, constatase que os bairros periféricos destacados como os menos incidentes de denunciação apresentam em sua maioria a violência física, enquanto os mais denunciadores a violência psicológica. 
A Lei Maria da Penha Auxiliando na Construção da Igualdade

de Gênero: uma análise da situação e percepção social da

violência doméstica contra a mulher em Campina Grande (PB)

Figura 02: Mapa da distribuição espacial das formas de violência doméstica contra mulher em Campina Grande-PB (2011 e 2012).

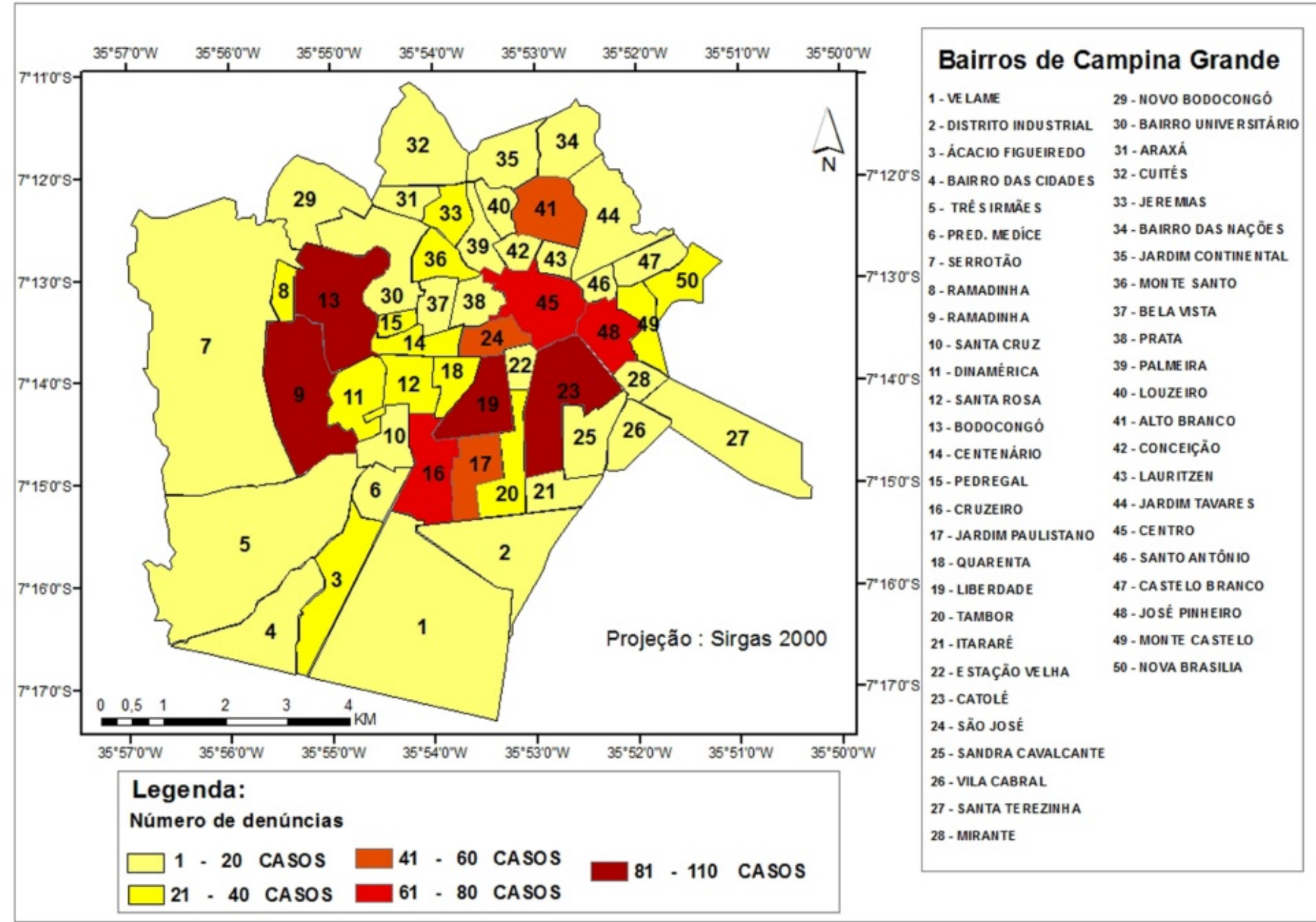

Tal premissa relaciona o fato de bairros periféricos da Cidade não apresentarem os maiores índices de denúncias e ao mesmo tempo um destaque quanto à forma de violência física, ao reconhecimento do que de fato se caracteriza como violência doméstica contra mulher pela população feminina, que efetiva a denúncia nestes locais. Este aspecto manifesta-se de forma mais explícita quando são observadas as diferenças sócioespaciais entre os bairros que mais se destacam em números de violência psicológica (mais denunciadores), com relação aos bairros que apresentam maior incidência da denúncia de violência física (menos denunciadores). $\mathrm{Ou}$ seja, existe um perfil das vítimas de violência doméstica que denunciam determinados tipos de formas de violência quanto a questões sociais, que reflete no conhecimento da Lei Maria da Penha?

A partir de tais discussões, verificou-se a necessidade de desenvolver análises de cunho fenomenológico nos bairros com maior e menor índice de denúncias. O principal intuito foi verificar o conhecimento da Lei Maria da Penha e os principais inibidores e propulsores da violência doméstica contra mulher na percepção da população feminina destes locais que, por conseguinte, apresenta tanto distinções de características 
sócioespaciais, quanto de incidência de denunciação.

Em um primeiro momento observou-se que o bairro do Catolé, além de exibir o maior índice de denúncia de violência doméstica contra mulher, dispõe de uma das maiores rendas domiciliares da Cidade (R\$ 3.211,42), enquanto o Três Irmãs, simultaneamente apresentou o menor índice de denúncia e uma das menores rendas $(\mathrm{R} \$$ 1.347,07), comprovando as distinções paralelas entre questões socioespaciais e de denunciação (IBGE, 2010).

Desta forma, a partir da percepção da população do Catolé e de Três Irmãs, por meio da aplicação de questionários e de uma análise de conteúdo foi possível compreender os níveis de conhecimentos diferenciados acerca da Lei Maria da Penha. Assim, considerou-se um alto nível quando era expresso pela maioria um conhecimento correto da Lei, um médio nível quando o conhecimento da Lei ocorria paralelamente a uma insuficiência da compreensão da mesma, e por fim um baixo nível quando a maioria da população demonstrou um conhecimento mínimo ou inexistente sobre os itens analisados acerca da referida Lei.

Para a organização dos itens utilizados na análise de conteúdo e identificação dos níveis diferenciados quanto ao conhecimento da Lei, utilizou-se das indicações de Franco (2004). Assim, chegou-se a seguinte análise dos níveis diferenciados de conhecimentos da Lei no Catolé e Três Irmãs.

Quadro 01: Síntese da análise acerca da percepção da Lei Maria da Penha por parte da população.

\begin{tabular}{|l|l|l|}
\hline Itens observados na percepção da população quanto a Lei Maria da Penha & Bairro \\
\cline { 2 - 3 } & Catolé & $\begin{array}{l}\text { Três } \\
\text { Irmãs }\end{array}$ \\
\hline $\begin{array}{l}\text { Lei Maria da Penha como um aparato preventivo e assistencial à vítima } \\
\text { feminina de violência doméstica. }\end{array}$ & \\
\hline $\begin{array}{l}\text { Reconhecimento das variadas formas de violência doméstica contra mulher } \\
\text { (física, psicológica, sexual, moral, patrimonial e outras). }\end{array}$ & \\
\hline $\begin{array}{l}\text { Conhecimento dos direitos assegurados à vítima de violência doméstica contra } \\
\text { mulher. }\end{array}$ & \\
\hline $\begin{array}{l}\text { Percepção de que podem ser aplicadas medidas de assistência social ao agressor } \\
\text { (programas de recuperação e reeducação). }\end{array}$ & \\
\hline $\begin{array}{l}\text { Impossibilidade de aplicação de medidas brandas ao agressor, como o } \\
\text { pagamento de cestas básicas. }\end{array}$ & \\
\hline $\begin{array}{l}\text { Reconhecimento de que o filho, irmão, pai, padrasto e outros indivíduos que } \\
\text { convivam em relação doméstica, familiar ou de afeto íntimo podem configurar o } \\
\text { pólo ativo nos casos de violência doméstica contra mulher. }\end{array}$ & \\
\hline $\begin{array}{l}\text { Reconhecimento da incidência da Lei Maria da Penha em casos de agressão no } \\
\text { seio de relação homoafetiva entre mulheres. }\end{array}$ & \\
\hline
\end{tabular}

\section{Legenda:}

Baixo Nível de Conhecimento

Médio Nível de Conhecimento

Alto Nível de Conhecimento 
Observaram-se consideráveis distinções relacionadas aos itens e aos bairros analisados. No Catolé, por exemplo, aspectos como a admissão das formas de violência previstas na correspondente Lei, o conhecimento dos direitos que assistem a mulher, a compreensão da impossibilidade na aplicação de medidas brandas em determinados casos, o entendimento dos possíveis tipos de agressores e as possibilidades de aplicação da Lei em casos de violência em relação homoafetiva, foram representados em alto grau de entendimento. Os únicos elementos referentes ao nível médio de compreensão dizem respeito à Lei como aparato preventivo e assistencial à vítima feminina de violência doméstica e à percepção de que podem ser aplicadas medidas de assistência social ao agressor, como programas de recuperação e reeducação.

Já no bairro Três Irmãs, o único fator que se manifestou em alto nível de entendimento por parte da população foi a compreensão de que não é mais possível a aplicação de medidas brandas ao agressor, como por exemplo, o pagamento de cestas básicas. O item que correspondeu a um entendimento médio refere-se ao reconhecimento de que o filho, irmão, pai, padrasto e outros indivíduos que convivam em relação doméstica, familiar ou de afeto íntimo podem configurar o pólo ativo nos casos de violência doméstica contra a mulher. Finalmente, quanto ao baixo índice de compreensão dos aspectos da Lei, destacase o aparato preventivo e assistencial à vítima feminina de violência doméstica, o reconhecimento das variadas formas de violência doméstica contra mulher, o conhecimento dos direitos assegurados à vítima, a percepção de que podem ser aplicadas medidas de assistência social ao agressor e o reconhecimento da incidência da Lei em casos de violência de relação homoafetiva entre mulheres.
Em síntese, no bairro do Catolé foi demonstrado um conhecimento dos aspectos normativos da Lei de forma bem mais expressiva em relação ao bairro Três Irmãs. De modo que o fato de o Catolé ser classificado como o mais incidente de denúncia pode estar relacionado diretamente ao conhecimento adquirido quanto a Lei. No bairro Três Irmãs, por sua vez, os baixos índices de denunciação podem condicionar uma dificuldade de reconhecimento dos locais onde de fato, ocorre a violência. Sendo assim, o baixo índice de denúncia pode disfarçar a prática da violência vivenciada nas localidades onde a população não detém o conhecimento acerca da Lei, e consequentemente, não utilizam seus pressupostos em uma perspectiva de proteção e punição. Assim, o conhecimento da Lei Maria da Penha, auxilia em fatores voltados desde a prevenção à proteção da mulher, auxiliando diretamente na igualdade entre os gêneros.

Tendo em vista estas discussões e afirmativas, chega-se a estruturação de um discurso da população feminina quanto aos fatores propulsores e inibidores da violência doméstica contra mulher por meio de uma aproximação e sobreposição de percepções e anseios em grupos focais. Assim, para a organização das informações referentes a esta etapa da pesquisa, utilizou-se da análise de discurso através das indicações de Lefévre e Lefévre (2003). No que tange ao discurso do sujeito coletivo, relacionado às ideias centrais referentes às percepções acerca dos propulsores e inibidores da violência doméstica contra mulher nos respectivos bairros, destacou-se diferentes impressões acerca dos principais questionamentos desenvolvidos para formulação deste resultado (Quadro 02). Paulatinamente, identificaram-se através de todas as técnicas empregadas durante os grupos focais tanto o discurso relativo a cada bairro, quanto à 
A Lei Maria da Penha Auxiliando na Construção da Igualdade

de Gênero: uma análise da situação e percepção social da

violência doméstica contra a mulher em Campina Grande (PB)

Quadro 02: Síntese do discurso do sujeito coletivo sobre propulsores e inibidores da violência doméstica contra mulher.

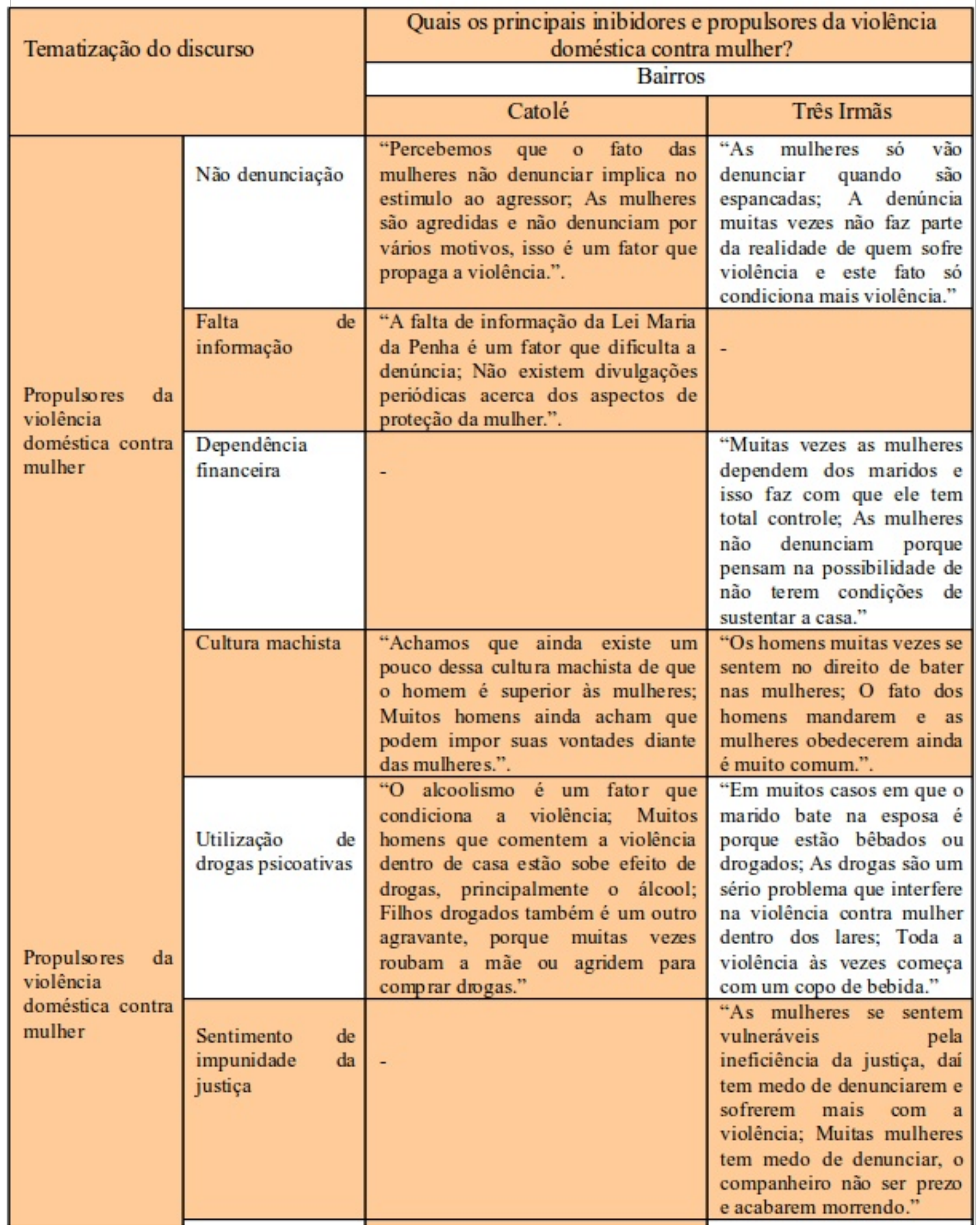

Antônio Cardoso Silva Filho e Janaína Barbosa Silva 
A Lei Maria da Penha Auxiliando na Construção da Igualdade

de Gênero: uma análise da situação e percepção social da

violência doméstica contra a mulher em Campina Grande (PB)

\begin{tabular}{|c|c|c|c|}
\hline & Traição conjugal & $\begin{array}{l}\text { "A traição também viabiliza várias } \\
\text { formas de violência contra mulher; A } \\
\text { motivação de uma situação constante } \\
\text { de violência contra mulher muitas } \\
\text { vezes sucede de traições entre os } \\
\text { casais." }\end{array}$ & $\begin{array}{l}\text { "A traição dos homens e das } \\
\text { mulheres resultam podem } \\
\text { resultar na violência; } \\
\text { Quando um homem } \\
\text { descon fia que ta sendo } \\
\text { traído pode até matar sua } \\
\text { companheira." }\end{array}$ \\
\hline & $\begin{array}{l}\text { Rompimento do } \\
\text { relacionamento }\end{array}$ & $\begin{array}{l}\text { "Em alguns momentos existem } \\
\text { perseguições de ex-companhei ros } \\
\text { após o término das relações; Muitos } \\
\text { homens inconformados com o fim da } \\
\text { relação colocam as mulheres em } \\
\text { situação de risco." }\end{array}$ & $\begin{array}{l}\text { "Aqui já ouvir falar de } \\
\text { sérias ameaças de } \\
\text { ex-companheiros } \\
\text { mulheres; As mulheres se } \\
\text { sentem inseguras em levar } \\
\text { suas vidas por pressão de } \\
\text { ex-companheiros." }\end{array}$ \\
\hline \multirow{6}{*}{$\begin{array}{l}\text { Inibidores da } \\
\text { violência } \\
\text { doméstica contra } \\
\text { mulher }\end{array}$} & Denúncia & $\begin{array}{l}\text { "Sem dúvida a denúncia é maior } \\
\text { forma de inibir este tipo de } \\
\text { violência; o homem que é } \\
\text { denunciado não terá tanta facilidade } \\
\text { em cometer o crime novamente." }\end{array}$ & $\begin{array}{l}\text { "Se todo mundo } \\
\text { denunciasse este tipo de } \\
\text { violência não seria tão } \\
\text { grande; Toda mulher vítima } \\
\text { de violência no lar tem que } \\
\text { denunciar." }\end{array}$ \\
\hline & $\begin{array}{l}\text { Políticas públicas } \\
\text { de prevenção e } \\
\text { combate }\end{array}$ & 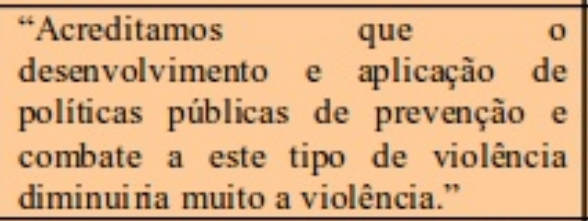 & 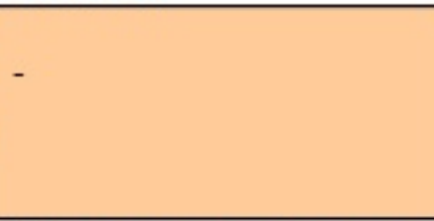 \\
\hline & $\begin{array}{l}\text { Aplicação de } \\
\text { medidas severas } \\
\text { aos agressores }\end{array}$ & $\begin{array}{l}\text { "Deve-se aplicar de forma séria a } \\
\text { punição do agressor." }\end{array}$ & $\begin{array}{l}\text { "Os agressores devem ser } \\
\text { penalizados de forma justa; } \\
\text { o homem que bate na } \\
\text { mulher merece o pior } \\
\text { julgamento da Lei." }\end{array}$ \\
\hline & $\begin{array}{l}\text { Divulgação de } \\
\text { informações sobre } \\
\text { a Lei }\end{array}$ & $\begin{array}{l}\text { "A disseminação de informações } \\
\text { sobre a Lei Maria da Penha é um } \\
\text { fator primordial no combate a } \\
\text { violência; Poderiam ser realizadas } \\
\text { campanhas de divulgação da Lei." }\end{array}$ & $\begin{array}{l}\text { "A falta de informação da } \\
\text { Lei implica muitas vezes na } \\
\text { violência doméstica contra } \\
\text { mulher; Se não há } \\
\text { informação da Lei a } \\
\text { possibilidade das pessoas } \\
\text { conhecerem diminuem." }\end{array}$ \\
\hline & Apoio familiar & 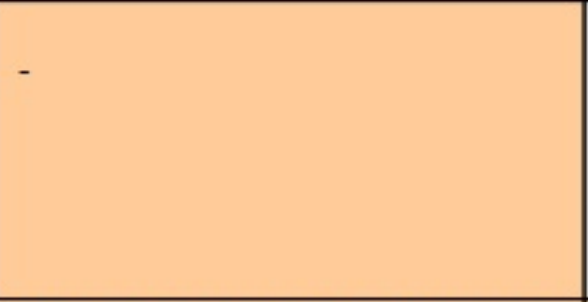 & $\begin{array}{l}\text { "O apoio familiar é muito } \\
\text { importante no processo que } \\
\text { inibi a violência doméstica } \\
\text { contra mulher; As mulheres } \\
\text { precisam ter apoio da } \\
\text { família no processo de } \\
\text { denúncia.". }\end{array}$ \\
\hline & $\begin{array}{l}\text { Maior } \\
\text { conhecimento } \\
\text { sobre os institutos } \\
\text { da Lei Maria da } \\
\text { Penha }\end{array}$ & $\begin{array}{l}\text { "O conhecimento das formas de } \\
\text { violelncia doméstica contra mulher e } \\
\text { das medidas de proteção da vítima e } \\
\text { punição do agressor possivelmente } \\
\text { diminui ria muito os casos de } \\
\text { violência ocorridos." }\end{array}$ & $\begin{array}{l}\text { "Talvez se as pessoas } \\
\text { conhecessem a Lei de forma } \\
\text { mais real, concreta, os casos } \\
\text { de violência doméstica } \\
\text { diminuiriam; Conhecer a } \\
\text { Lei significa se proteger da } \\
\text { violência." }\end{array}$ \\
\hline
\end{tabular}

Antônio Cardoso Silva Filho e Janaína Barbosa Silva 
tematização destes, que por sua vez, corresponde ao tema geral do qual o discurso está relacionado.

Nesta perspectiva, quanto aos fatores que impulsionam e inibem a violência doméstica contra mulher verificaram-se distorções entre o Catolé e Três Irmãs. O catolé proferiu discursos acerca dos fatores propulsores da violência doméstica relacionados a não denunciação, falta de informação, cultura machista, utilização de drogas psicoativas, traição conjugal e o rompimento do relacionamento. Quanto ao Três Irmãs, destacaram-se neste item a não denunciação, dependência financeira, cultura machista, utilização de drogas psicoativas, sentimento de impunidade da justiça, traição conjugal e rompimento do relacionamento. Ademais, quanto aos condicionantes inibidores, no Catolé foi destacada a denúncia, políticas públicas de prevenção e combate, aplicação de medidas severas aos agressores, divulgação de informações sobre a Lei e o maior conhecimento sobre os institutos da Lei Maria da Penha. No Três Irmãs, por sua vez, destacaram-se a denúncia, a aplicação de medidas severas aos agressores, a divulgação de informações sobre a Lei e o maior conhecimento sobre os institutos desta.

Em todos os itens, a percepção da população dos Bairros se manifestou de maneira diferenciada. No entanto, nos dois bairros foram destacados elementos diferentes entre si, no Catolé, especialmente, foi ressaltada em termos de propulsor da violência a falta de informação, enquanto no Três Irmãs a dependência financeira e o sentimento de impunidade da justiça. Já no que tange aos inibidores, no Catolé foi indicado às políticas públicas de prevenção $\mathrm{e}$ combate a violência, já nos três irmãs o apoio familiar.

Esses fatores referentes à percepção social quanto a Lei Maria da Penha também são aspectos que condicionam algum grau do contexto vivenciado nos correspondentes bairros vinculados a violência doméstica contra mulher. Neste caso, não é valido à estruturação de um olhar que determine qual localidade apresenta uma maior validade acerca dos inibidores e propulsores da violência doméstica contra mulher, uma vez que os anseios, a situação social e os níveis de conhecimentos da Lei se manifestam diferencialmente. Logo, os fatores destacados como propulsores e inibidores para esta pesquisa serve, principalmente, como aporte para a análise que reconhece as distinções discursivas entre os bairros que apresentaram maiores e menores índices de violência doméstica contra mulher.

Através de todas estas constatações, ressalta-se mais uma vez se, de fato, no bairro com condições menos favorecidas existe um menor quantitativo de violência acometida, ou um menor índice de denúncia resultante do não conhecimento da Lei e de questões socioeconômicas. Desta forma, sustenta-se o pressuposto de que a Lei e o seu conhecimento e percepção popular contribui indiscriminadamente para a construção da igualdade de gênero.

Todas essas constatações incidem em meio à conjuntura interdisciplinar desta análise, que além de demonstrar que a associação de fatores relacionados ao conhecimento da Lei e as condições socioeconômicas interferem nos índices de denunciação, corrobora também para a aceitação do pressuposto de que a formulação, aplicação e, sobretudo, o conhecimento da Lei Maria da Penha possa contribuir ao mesmo tempo para a redução dos índices de violência e aumento dos níveis de denúncias.

A tentativa de construção da igualdade de gênero está explicita em diversas formas de manifestação política, social e cientifica, devendo significar a igualdade de direitos e de defesa, a liberdade e oportunidades de participação, o reconhecimento e valorização 
dos homens e das mulheres em todos os domínios da sociedade, dentre eles o familiar.

\section{Considerações Finais}

Diante da sistematização dos dados e informações da pesquisa, observou-se que o bairro do Catolé sucede como o mais incidente de denúncias, enquanto o Três Irmãs o menos incidente.

Quanto às formas de violência, verificouse que a mais preponderante na Cidade é a psicológica, porém, na maioria dos bairros com menor incidência destacou-se a violência física como a mais perpetrada. Estas localidades, por sua vez, demonstraram conhecimentos diferenciados acerca da Lei, como também apresentam diferenciações socioeconômicas, onde se identificou uma relação direta entre maior renda com melhor reconhecimento da Lei.

Por meio destas afirmativas, levantam-se questionamentos que vão relacionar as denúncias ao nível de conhecimento da Lei e da percepção social acerca dos principais propulsores e inibidores da violência doméstica contra mulher, além de questões socioeconômicas. Onde ocorre o menor índice de denúncia, de fato manifesta o menor quantitativo de violência doméstica?

Nesta perspectiva, atentando para uma percepção social quanto a Lei Maria da Penha e sua interferência na construção da igualdade de gênero em Campina Grande$\mathrm{PB}$, observaram-se distorções discursivas do Catolé e Três Irmãs quanto aos principais propulsores e inibidores deste tipo de crime.

Ademais, a consolidação interdisciplinar desta análise ressalta que diversos fatores devem ser associados em uma análise que busque um entendimento de um fator tão complexo, como a violência doméstica contra mulher.

\section{Referências}

ABDALA, Cláudia; SILVEIRA, Kátia; MINAYO, Maria Cécilia Souza. Aplicação da Lei Maria da Penha nas delegacias de mulher: O caso do Rio de Janeiro. Dilemas: Revista de Estudos de Conflito e Controle Social, v. 4. n. 4, p. 571 - 600, 2011.

ANDALAFT, Jorge; FAÚNDES, Anibal. A violencia sexual y la respuesta del setor salud en Brasil. In: SIMPÓSIO SOBRE VIOLENCIA DE GENERO, SALUD Y DERECHOS EN LAS AMÉRICAS, 2001. Cancún. Anais. 2001.

BIANCHINI, Alice. Lei Maria da Penha: Lei 11.340/2006: aspectos assistenciais, protetivos e criminais da violência de gênero. $1^{\text {a }}$ Ed. São Paulo: Saraiva, 2013.

FRANCO, Maria Laura Barbosa. Análise de conteúdo. 2. ed. Brasília: Liber Livro Editora, 2005.

GRECO, Rogerio. Curso de Direito Penal: introdução à teoria geral da parte especial - crimes contra a pessoa. Niterói, RJ: Impetus, 2010.

IBGE/Instituto Brasileiro de Geografia e Estatística. Senso demográfico 2010. Disponível em: $<$ http://www.sidra.ibge.gov.br $>$. Acesso em 12 de Setembro de 2013.

JESUS, Damásio. Violência Contra a Mulher: aspectos criminais da Lei 11.340/2006. São Paulo: Saraiva, 2010.

JOHNSON, Allan. The Gender Knot. Unraveling our patriarchal legacy. Philadelphia: Temple University Press, 1997.

LACAN, Jacques. Feminine Sexuality. 
Inglaterra: Pitman Press Beaconsfield, 1982.

LAURETIS, Teresa. 'A tecnologia de gênero'. In: HOLLANDA, Buarque (Org.). Tendências e impasses. $O$ feminismo como crítica da cultura. Rio de Janeiro: Rocco, 1987, p. $206-242$.

LEFÈVRE, Fernando; LEFÈVRE, Ana Maria Cavalcanti. Discurso do sujeito coletivo: um novo enfoque em pesquisa qualitativa (desdobramentos). Caxias do Sul: EDUCS, 2003.

LEGISLAÇÃO DA MULHER. - 3. Ed. Brasília: Câmara dos Deputados, Edições Câmara, 2010. (Série Legislação; n. 29).

LEME, Taciana Neto. Os conhecimentos práticos dos professores: (re) abrindo caminhos para a educação ambiental na escola. São Paulo: Annablume, 2006.

LERNER, Gerda. The Creation of Patriarchy. Oxford: Oxford University Press, 1986.

MATOS, Marlene. Avaliação Psicológica de Vítimas de Violência Doméstica. In: MATOS, Marlene; GONÇALVES, Rui Abrunhosa; MACHADO, Carla (Eds.). Manual de Psicologia Forense: Contextos, práticas e desafios. Braga: Psiquilíbrios Edições, 2011, p. 175 - 197.

MINAYO, Maria Cecília de Sousa. Violência social sob a perspectiva da saúde pública. Cad. Saúde Pública, v. 10, p. 7 - 18, 1994.

MINAYO, Maria Cecília de Souza; ASSIS, Simone Gonçalves de; SOUZA, Edinilza Ramos de (Orgs). Avaliação por triangulação de métodos: abordagem de programas sociais. Rio de Janeiro: Editora Fiocruz, 2005.
MINAYO, Maria Cecilia Sousa. Violência e Saúde. Rio de Janeiro: Editora Fiocruz, 2006.

NEY, Andrea. Teoria feminista e as filosofias do homem. Rio de Janeiro: Rosa dos tempos, 1995.

PANDOLFI, Dulce Chaves. Percepção dos direitos e participação social. In: CARNEIRO, Leandro Piquet; GRYNSZPAN, Mário; CARVALHO, José Murilo de; PANDOLFI, Dulce. Cidadania, justiça e violência. Rio de Janeiro: Editora Fundação Getúlio Vargas, 1999, p. 45 - 58.

PARODI, Ana Cecília; GAMA, Rodrigues Gama. Lei Maria da Penha, Comentários á Lei $\mathbf{n}^{\circ}$ 11.340/2006. São Paulo: Russel Editores, 2009.

ROLIM, Renata. Ribeiro. Gênero, Direito e esfera pública: Condições de efetividade da Lei Maria da Penha. Rev. Direito Mauricio de Nassau, v. 3, n. 3, p. 229 - 353, 2008.

SAFFIOTI, Heleieth. Gênero, patriarcado, violência. São Paulo: Fundação Perseu Abramo, 2004.

SANTOS, Milton. Pensando o espaço do homem. São Paulo: Edusp, 2009.

SCOTT, Joan. Gender: a useful category of historical analysis. In: SCOTT, Joan. Gender and the politics of history. New York: Columbia University Press, 1988, p. 28 - 52.

TELES, Maria Amélia de A.; MELO, Mônica de. O que é violência contra a mulher. São Paulo: Brasiliense, 2004.

Recebido em 02 de fevereiro de 2014. Aceito em 05 de junho de 2014. 